\title{
Ring XY bivalent: a new phenomenon at metaphase I of meiosis in man
}

\author{
ANN C CHANDLEY, T B HARGREAVE*, S McBEATH, \\ A R MITCHELL, AND R M SPEED
}

From the MRC Clinical and Population Cytogenetics Unit, and ${ }^{*}$ the University of Edinburgh Department of Surgery (Urology), Western General Hospital, Edinburgh EH4 $2 X U$.

SUMMARY The unusual appearance of a ring XY bivalent at metaphase I of meiosis is reported in some cells of an oligospermic human male. Higher than usual frequencies of ring configuration in the XY pair were also observed during prophase I. The defect could be attributable to loss of some DNA sequences from the distal heterochromatic tip of the Y chromosome long arm.

A meiotic phenomenon which, as far as we are aware, has never previously been reported in man was recorded recently in the metaphase I primary spermatocytes of a male infertility patient. The sex bivalent, instead of appearing in its usual chain-like form with end to end association of the $\mathrm{X}$ and $\mathrm{Y}$ chromosome short arms, was seen in about $5 \%$ of cells to make a ring; secondary association was occurring also at the long arm distal tips. Such associations are a fairly regular feature of the $\mathrm{XY}$ pair at early pachytene in man, ${ }^{1}$ but by meiotic metaphase I the situation is normally resolved and the sex chromosomes appear held together in tandem only by their short arm distal tips. Not only were ring $X Y$ bivalents seen at metaphase $I$ in this unusual subject, but at the pachytene stage a much higher than normal frequency of ring configurations in the sex pair was also found.

To investigate whether a defect existed in the distal tip of the $\mathrm{Y}$ chromosome long arm, meiotic preparations were examined by in situ hybridisation using the cloned probe pHY $2 \cdot 1$. The data could indicate loss of DNA sequences from the heterochromatic tip of $\mathrm{Yq}$ although other explanations are offered.

\section{Case report}

The patient (WSM 175), a 23 year old phenotypically normal male, presented at the Infertility Clinic of the Western General Hospital, Edinburgh in April 1984. He was a healthy man employed as a labourer, who reported he had suffered no serious adult illnesses. Height was $170 \mathrm{~cm}$ and weight $85 \cdot 3 \mathrm{~kg}$.

Received for publication 16 September 1985.

Revised version accepted for publication 1 November 1985.
Both testes were of normal size and consistency and the penis and scrotum were normal.

SEMINAL ANALYSIS

A single semen sample, taken when the patient first reported at the clinic, showed severe oligospermia, the sperm count being only $1 \times 10^{6}$ per ml (morphology $55 \%$ normal, motility $80 \%$ normal).

\section{TESTICULAR HISTOLOGY}

A testicular biopsy, taken in October 1984, showed a very variegated histological appearance in the seminiferous tubules. Some lobules of cystic parenchyma appeared to consist solely of extensively hyalinised tubules. These were of small calibre and showed either complete absence of germinal epithelium or a markedly degenerate epithelial lining consisting of a few spermatogonia or Sertoli cells only. The tunica propria of these tubules was thickened.

Other larger tubules occupied most of the biopsy, these being lined by a normal germinal epithelium which in about $60 \%$ of cases showed normal spermatogenesis with mature spermatozoa. Even in these, however, there was evidence of maturation arrest at the secondary spermatocyte level. Other large tubules were distended and showed marked compression of their germinal component. Leydig cells were more prominent than usual.

\section{Methods}

CYTOGENETIC ANALYSIS

Somatic chromosomes

Chromsome analysis on peripheral blood lympho- 
cytes of WSM 175 was performed using standard techniques. $\mathrm{G}$ banding, ${ }^{2} \mathrm{C}$ banding, ${ }^{3}$ and kinetochore staining ${ }^{4}$ techniques were all applied.

\section{Meiotic chromosomes}

Metaphase I. Analysis of metaphase I divisions was performed on conventional air dried preparations ${ }^{5}$ stained with carbol fuchsin. For unambiguous identification of the ring $X Y$ bivalent, prefluorescence using distamycin A/DAPI ${ }^{6}$ was performed on additional slides. Cells in which a ring XY was identified by fluorescence were photographed, relocated after carbol fuchsin staining, and rephotographed.

Pachytene analysis. Microspread preparations of pachytene spermatocytes were made on Parlodion coated slides, stained with silver nitrate, ${ }^{7}$ and examined at the electron microscope level. Spreads were first selected in the light microscope and cut from the film using a Leitz diamond slide marker. The small round discs were floated off the slides onto distilled water and picked up on $\mathrm{G} 200 \mathrm{HsCu}$ (Gilder) grids. Grids were examined with a Philips EM 300 at $60 \mathrm{kV}$.

\section{IN SITU HYBRIDISATION}

Air dried meiotic metaphase I cells from WSM 175 and a chromosomally normal control (WSM 179), ascertained two and a half months later, were probed using the cloned probe pHY $2 \cdot 1$. All slides were stored in a desiccator under vacuum at $4^{\circ} \mathrm{C}$ until being used for the experiment. This sequence is located in the most distal region of Yq1.2. Hybridisation in situ was carried out as described previously. ${ }^{9-11}$ Slides were developed after one, two, three, four, 25 , and 40 days exposure and the chromosomes were stained through the emulsion using Wright's stain. ${ }^{9}$ To allow an impartial analysis, each slide was coded and scored blind by a single observer.

\section{Results}

BLOOD LYMPHOCYTE CHROMOSOME

ANALYSIS

A total of $10 \mathrm{G}$ banded cells from WSM 175 was analysed. All showed a normal 46,XY karyotype. The Y chromosome was normal in appearance and well within normal size limits ( $G$ group size range). Additional cells analysed by $C$ banding and kinetochore staining showed the $\mathrm{Y}$ chromosome to be apparently normal in structure. A scan of all suitable metaphases on one slide $(n=>100)$ gave no indication of any association between the $\mathrm{Y}$ chromosome and other chromosomes in the complement.

The Y chromosome of the control male WSM 179 was also normal in appearance and size ( $G$ group $\overrightarrow{\vec{F}}$ range).

\section{MEIOTIC CHROMOSOME ANALYSIS}

Air dried preparations

A normal meiotic picture was present in this patient,,$\widehat{Q}$ other than the occurrence of the ring XY bivalent ines some cells at metaphase I (MI). A distribution countof 300 dividing cells in spermatogonial mitosis, $\mathrm{MI}$ and MII showed proportions well within normal limits. The frequency of univalent $\mathrm{X}$ and $\mathrm{Y}$ chromos somes $(6.8 \%)$ was also within normal limits, and chiasma counts made on 10 cells at MI gave \% normal mean value of 53.4 chiasmata per cell

The only exceptional feature at meiosis, therefore, was the ring XY bivalent which was first noted $\vec{P}$ in a clear, well spread MI cell, stained with carbob fuchsin, and showing 23 bivalents but absence of $a_{-}$ normal chain $X Y$ bivalent (fig 1). Subsequent analysis revealed that a total of 13 out of $268(4.9 \%)$ D MI cells in these preparations, all with normas counts of 23 , lacked a chain XY bivalent. Unambi guous identification of the ring XY bivalent in a cell prefluoresced using distamycin A/DAPI is shown inpo fig 2. A single fluorescent segment corresponding to Yqh can be seen in one ring bivalent.

Quite fortuitously, meiotic air dried slides of WSM 175 had been used in an in situ hybridisationo experiment unconnected with the present investi: gation. ${ }^{11}$ Here, the highly repeated cloned probea

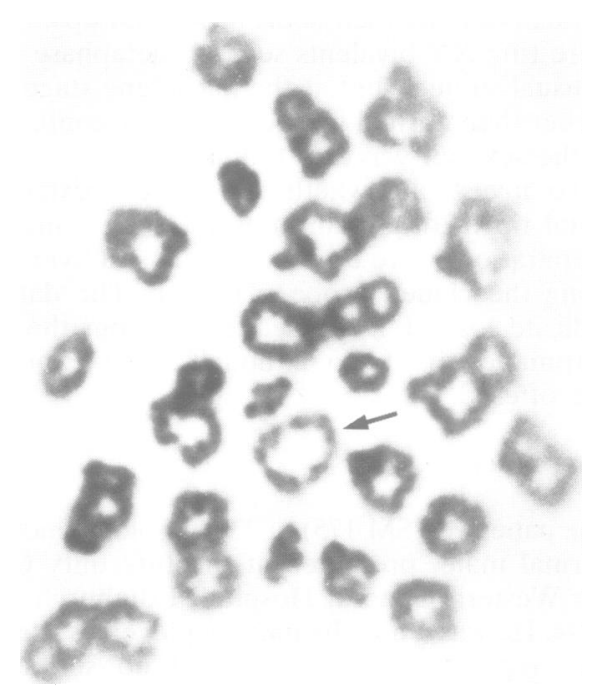

FIG 1 Air dried meiotic metaphase I stained with carbo fuchsin. The presumed $X Y$ bivalent is arrowed. 

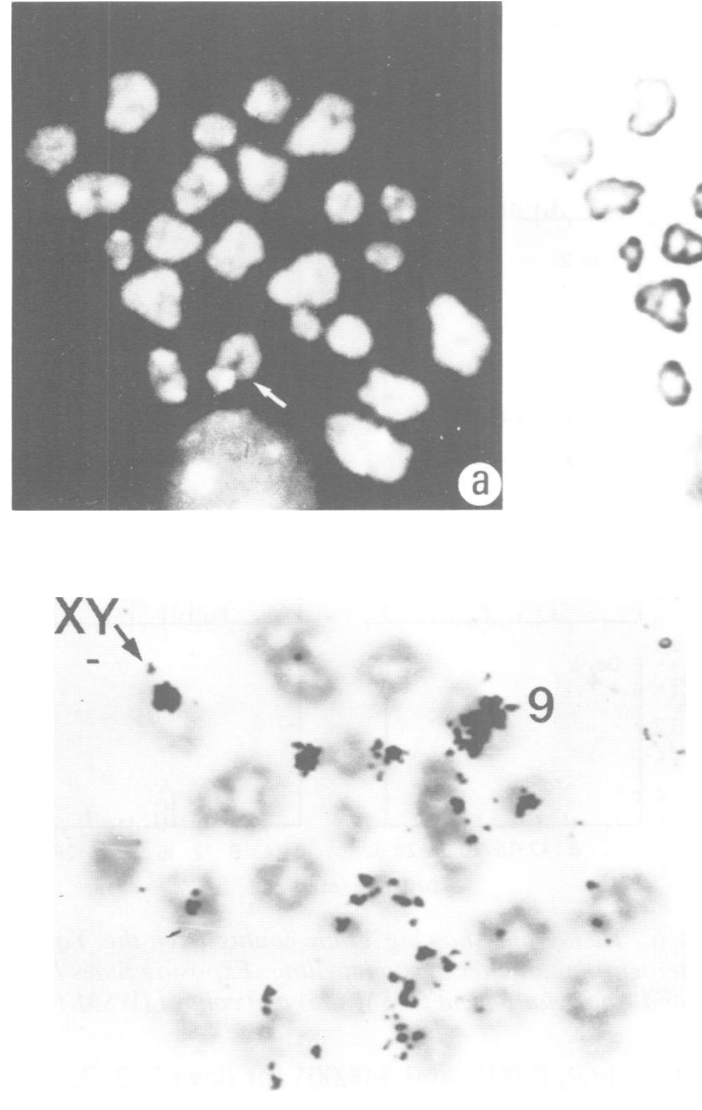

FIG 3 In situ hybridisation of cloned probe $X b_{1}$ to $M I$ cell of WSM 175. The single heavy signal over the $Y q$ heterochromatin in one ring bivalent identifies it as the ring $X Y$. Heavy labelling also characterises bivalent No 9.
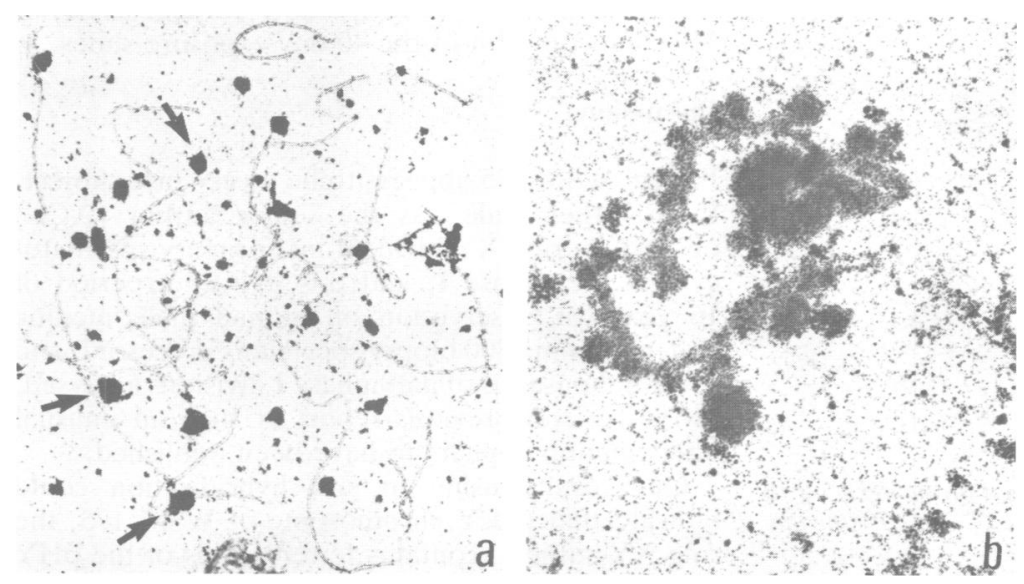

FIG 2 MI stained consecutively with (a) distamycin A/DAPI and (b) carbol fuchsin. The ring $X Y$ bivalent is arrowed.

$\mathrm{Xb}_{1}$, which hybridises to the long arm heterochromatin of the $\mathrm{Y}$ chromosome (as well as to the secondary constriction of chromosome 9), had been used. Cells containing the ring XY bivalent clearly showed a single hot spot of label over Yqh by which the sex bivalent could be identified (fig 3 ).

\section{Pachytene analysis}

Among 50 pachytene cells in which the XY pair could be classified according to the types $\mathrm{O}$ to $\mathrm{V}$ of Solari, ${ }^{12}$ in addition to the usual association at the short arms where a synaptonemal complex occurs, secondary association between the long arm tips was found in $81 \%$ of early to mid-pachytene nuclei (types I and II). This compares with the usual frequency of long arm/long arm association of about $50 \%$ recorded in our own laboratory at these stages for chromosomally normal persons.

A very high proportion $(70 \%)$ of all pachytenes examined at electron microscope level by spreading were degenerate looking, heavily deposited with

FIG 4 (a) Whole pachytene cell from EM spread preparation. Heavy deposits of silver positive material are seen scattered within the nucleus (arrows). (b) The $X Y$ pair at pachytene in a spread preparation (EM). Heavy deposits of silver positive material are present on the differential axes. 
silver positive NOR-like material, and showed poorly defined synaptonemal complexes (fig 4). We concluded that such cells were destined for maturation breakdown and would contribute significantly to the severe oligospermia of the patient. Maturation arrest of a proportion of cells was indeed noted, from the histological report, to be occurring at the secondary spermatocyte levels. The XY differential segments in many cells were also seen in this patient to be more than usually deposited with silver positive material or excrescences (fig $4 \mathrm{~b}$ ), but the significance of this in relation to the ring $\mathrm{XY}$ formation is not clear.

\section{In situ hybridisation}

Hybridisation of the probe $\mathrm{pHY} 2 \cdot 1$ to the $\mathrm{Y}$ chromosome at meiosis in WSM 179 is shown in fig 5 , following a one day exposure to autoradiographic film. At this short exposure time, individual grains were countable in most cells from the two patients, but as exposure times increased so grains tended to coalesce and become uncountable in an increasing proportion of cells.

Grain count results from WSM 175 and WSM 179, developed after one, two, three, and four days of exposure are presented as a histogram in fig 6 . Background counts for both patients were negligible. Statistical analysis using the Mann-Whitney U test showed that the difference in total grains recorded between the patient (WSM 175) and his control (WSM 179) was highly significant. Values of $p$ were

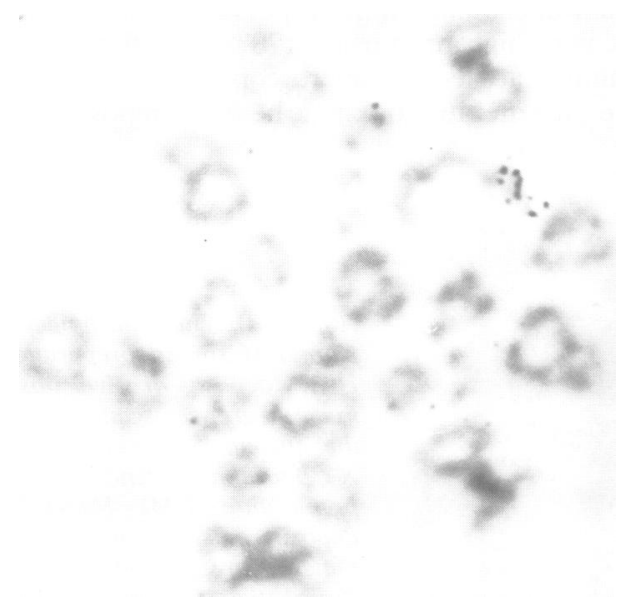

FIG 5 In situ hybridisation of the cloned probe $\mathrm{pHY} 2 \cdot 1$ to the distal tip of Yqh at MI in the control WSM 179. One day exposure.

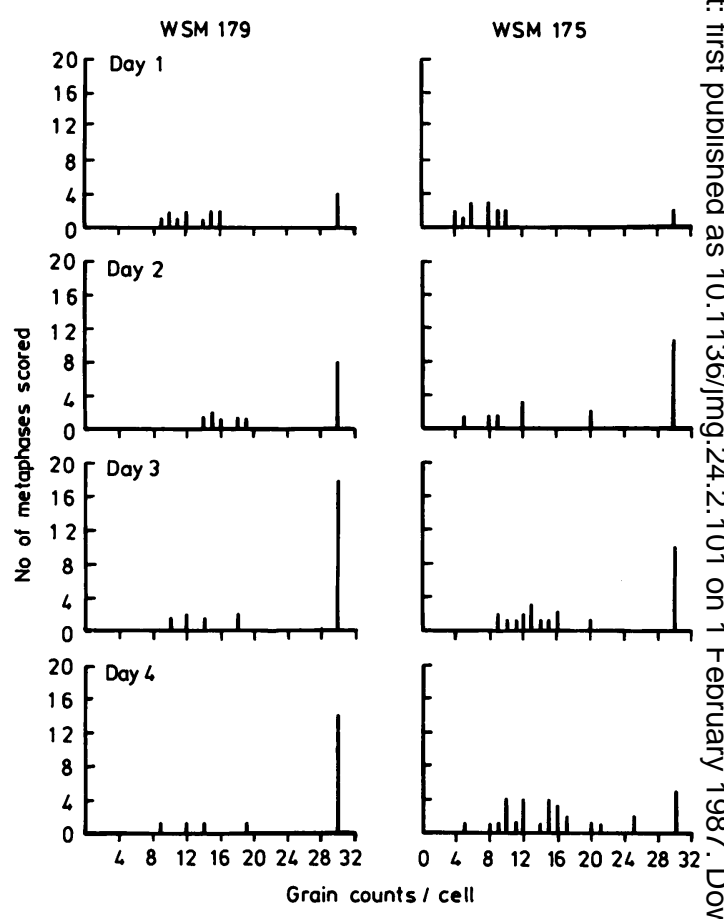

FIG 6 Histogram showing grain counts over the $Y q$ heterochromatin after in situ labelling. Exposure times 1, 2, 3 , and 4 days for patient (WSM 175) and control (WSM 179)요

$0 \cdot 001,0 \cdot 69,0 \cdot 001$, and 0.00001 for days $1,2,3$, and $\overrightarrow{\vec{\rho}}$ 4 respectively.

After an exposure period of 40 days, the dista居 heterochromatin of $\mathrm{Yq}$ was extremely heavily labelled both in WSM 175 and WSM 179. By this time some autosomes were also becoming clearly labelled. No secondary site of label was seen however, on the XY bivalent in either patient, in spite of examining a considerable number $(>80)$ o\$ MI plates on each of the $\mathbf{4 0}$ day exposure slides.

\section{Discussion}

Patient WSM 175 appears to be a very rare subject In no other male has the senior author (ACC $\overline{\text { D }}$ observed a ring XY bivalent in a primary spermatoN cyte at metaphase $I$, and this is over a period of 16 years of observation on human male meiotice material, some 800 biopsy specimens processed, an $\&$ several thousands of metaphase I divisions analysed Moreover, no previous report of such an unusual phenomenon appears to have been published.

Our results using in situ hybridisation coul indicate that the Y chromosome of WSM 175, the ring $X Y$ subject, contains fewer copies of the $\mathrm{pHY}$ 
$2 \cdot 1$ DNA sequences than the $\mathrm{Y}$ chromosome of a normal male. Previous studies ${ }^{13}$ have shown that $Y$ chromosome variants lacking part or all of the fluorescent region of the long arm of the $\mathrm{Y}$ chromosome contain fewer copies of the repeated DNA sequences represented by probe $\mathrm{pHY} 2 \cdot 1$. One interpretation of the data, therefore, could be that the Y chromosome of WSM 175 is a variant which has lost chromatin containing at least a proportion of the pHY $2 \cdot 1$ probe DNA sequences. The loss in this case, however, was imperceptible cytologically.

It is also possible that the lower grain counts obtained for WSM 175 could be due simply to between patient or between preparation variability. In situ hybridisation is notoriously variable as a technique, with variation in grain counts occurring between different sets of slides. The original air dried meiotic preparations used in the present investigation were made with a 2.5 month interval separating them, and the different levels of hybridisation obtained could be attributable to this fact. Variation in hybridisation could also occur between individual men with normal looking $\mathrm{Y}$ chromosomes, even if slides were prepared at the same time. It is of interest, nevertheless, to ask if there could be a correlation between the rare event of finding a ring $\mathrm{XY}$ bivalent and loss of chromatin containing a repeat DNA sequence localised in the telomeric region of the $\mathrm{Y}$ chromosome. One explanation could be that a translocation event has occurred between $\mathrm{Yq}$ and $\mathrm{Xq}$. Although the ring $\mathrm{XY}$ was noted in approximately $80 \%$ of the cells in pachytene, only $5 \%$ of the rings remained in MI. Those bivalents of WSM 175 which demonstrated a chain configuration in MI (95\% of the cells) did not show any labelling of $\mathrm{Xq}$. Thus, we would rule out the possibility that a translocation event had taken place.

Alternatively, an intercalary deletion within the fluorescent region of the long arm of the $Y$ chromosome, with the specific telomere sequence undergoing translocation to the now deleted portion of the $\mathrm{Y}$ chromosome, may have occurred. We know that telomeres are important for DNA replication ${ }^{14}$ and models explaining their role in this procedure have been proposed. ${ }^{15} \mathrm{~A}$ third possibility is, therefore, that the $\mathrm{Y}$ chromosome long arm contains latent telomeric sequences which can be activated when a deletion event takes place within the fluorescent long arm, which would then allow replication to occur. Although the last proposal lacks experimental evidence, it might suggest either that repeated DNA sequences, specifically those represented by the 2000 copies of the $\mathrm{pHY} 2 \cdot 1$ probe present on the $\mathrm{Y}$ chromosome, are involved in the function of the telomere, or that telomeric sequences are closely associated with these repeated DNA sequences. It is possible that the telomeric sequence in WSM 175 was located within the deleted chromatin and that this has made the Yq tip less stable with the subsequent formation of a ring $\mathrm{XY}$ bivalent. No stickiness which might have caused association between Yqh and other chromosomes in the somatic complement was apparently produced.

Finally, our results using the probe pHY $2 \cdot 1$ have confirmed the observations of Cooke et al ${ }^{8}$ showing that it hybridises predominantly to the tip of $\mathrm{Yq} 1 \cdot 2$. We differ, however, from Cooke et $^{8} \mathrm{l}^{8}$ who reported that this sequence was also present on the $X$ chromosome. We did not detect this sequence on the $\mathrm{X}$ chromosome even after a 40 day exposure time, when the autosomes were clearly becoming specifically labelled. Because of the period of time left for grains to develop, the number of slides examined, and the number of metaphases scored, we must conclude that this sequence is absent from the $\mathrm{X}$ chromosome. Somatic cell hybrids containing only the human $\mathrm{X}$ chromosome have recently been probed with pHY $2 \cdot 1$ and no signal has been detected (H J Cooke, 1985, personal communication), supporting the above conclusion.

The authors are grateful to Dr A Carothers for carrying out the statistical analysis, to Dr A Busuttil (Pathology Department, Western General Hospital) for the histological report, and to Sandy Bruce of the MRC Photographic Department for the preparation of figures.

\footnotetext{
References

${ }^{1}$ Chandley AC, Goetz P, Hargreave TB, Joseph AM, Speed $R M$. On the nature and extent of $X Y$ pairing at meiotic prophase in man. Cytogenet Cell Genet 1984;38:241-7.

2 Sumner AT, Evans HJ, Buckland RA. New techniques for distinguishing between human chromosomes. Nature 1971;232: $31-2$.

${ }^{3}$ Sumner AT. A simple technique for demonstrating centromeric heterocromatin. Exp Cell Res 1972;75:304-6.

${ }^{4}$ Denton TE, Brooke WR, Howell WM. A technique for the simultaneous staining of both nucleolar organizer regions and kinetochore of human chromosomes with silver. Stain Technol 1977;52:311-3.

5 Evans EP, Breckon G, Ford CE. An air-drying method for meiotic preparations from mammalian testes. Cytogenetics 1964;3:289-94.

- Schweizer D, Ambros P, Andrie M. Modification of DAPI banding on human chromosomes by prestaining with a DNAbinding oligopeptide antibiotic, distamycin A. Exp Cell Res 1978;111:327-32.

7 Howell WM, Black DA. Controlled silver staining of nucleolus organizer regions with a protective colloidal developer: a onestep method. Experientia 1980;36:1014-5.

${ }^{8}$ Cooke HJ, Schmidtke J, Gosden JR. Characterisation of a human $\mathrm{Y}$ chromosome repeated sequence and related sequences in higher primates. Chromosoma 1982;87:491-502.
} 
${ }^{9}$ Joseph AM, Gosden JR, Chandley AC. Estimation of aneuploidy levels in human spermatozoa using chromosome specific probes and in situ hybridization. Hum Genet 1984;66: 234-8.

${ }^{10}$ Mitchell AR, Gosden JR, Miller DA. p82H: a cloned sequence of the alphoid repeated DNA family found at the centromeres of all human chromosomes. Chromosoma 1985;92:369-77.

"Mitchell AR, Ambros P, McBeath S. Chandley AC. Molecular hybridisation to meiotic chromosomes in man reveals sequence arrangement on the No 9 chromosome and provides clues to the nature of 'parameres'. Cytogenet Cell Genet 1986;41:89-95.

12 Solari AJ. Synaptonemal complexes and associated structures in microspread human spermatocytes. Chromosoma 1980;81:31537.
${ }^{13}$ Gosden JR, Gosden CM, Christie S, Cooke HJ, Morsman JME Rodeck $\mathrm{CH}$. The use of cloned Y chromosome specific DN probes for fetal sex determination in first trimester prenat $\$$ diagnosis. Hum Genet 1984;66:347-51.

${ }^{14}$ Cavalier-Smith T. Palindromic base sequences and replication of eukaryote chromosome ends. Nature 1974;250:467-70.

15 Dancis BM, Holmquist GP. Telomere replication and fusion i⿱乛龰 eukaryotes. J Theor Biol 1979;78:211-24.

Correspondence and requests for reprints to $\mathrm{Dr} A \mathrm{CH}$ Chandley, MRC Clinical and Population Cytogenetics Unit, Western General Hospital, Edinburghw EH4 2XU. 